\title{
Adsorption of Polar Organic Compounds on Oxidized Iron Surface and the HSAB Principle
}

\author{
Katsumi Higashi*, Hiroshi Nishihara* and Kunitsugu Aramaki* \\ *Faculty of Science and Technology, Keio University
}

\begin{abstract}
Inhibition efficiencies of polar organic compounds for the corrosion of various metals in acid solutions are related to the hard and soft acids and bases principle (HSAB principle). Since a bulk metal is classified to a soft acid, the compound acting as a soft base is more readily chemisorbed on surface of the metal than that of a hard base, resulting in the higher inhibition efficiency. In this paper, effect of the polar organic compounds on current densities of Fe electrode in active and passive region of anodic polarization curves and amount of the compounds adsorbed on $\gamma-\mathrm{Fe}_{2} \mathrm{O}_{3}$ powder are discussed on the basis of the HSAB principle. The compounds, $\left(n-\mathrm{C}_{4} \mathrm{H}_{9}\right)_{3} \mathrm{X}(\mathrm{X}=\mathrm{N}$, $\mathrm{P}, \mathrm{As}$, and $\mathrm{Sb}$ ) were used as the inhibitors. The polatization measurements were carried out on $99.99 \% \mathrm{Fe}$ in deaerated $3.0 \mathrm{M} \mathrm{HC1O}_{4}$ and boric-borate buffer $(\mathrm{pH} 8.45)$ at $30^{\circ} \mathrm{C}$. The surface coverages of the compounds were obtained on the powder of $99.9 \% \gamma-\mathrm{Fe}_{2} \mathrm{O}_{3}$ in methanol by HPLC. The inhibitor acting as the soft base was effective for the dissolution of $\mathrm{Fe}$ in $\mathrm{HClO}_{4}$ than that of the hard base, indicating the agreement with the previous results. The passive current density of $\mathrm{Fe}$ electrode in the buffer solution decreased by the addition of $R_{3} N$ and $R_{3} P$ while increased by the addition of $\mathbf{R}_{3} \mathrm{As}$ and $\mathbf{R}_{3} \mathrm{Sb}$. This result suggested that the compound classified to the hard base was adsorbed on the oxidized $\mathrm{Fe}$ surface acting as the hard acid to more extent than that classified to the soft base. The compound of the hard base was readily chemisorbed on the surface of $\gamma-\mathrm{Fe}_{2} \mathrm{O}_{3}$ powder acting as the hard acid. The adsorption behavior of the polar organic compounds on the oxidized $\mathrm{Fe}$ surface was concluded to be closely related to the HSAB principle.
\end{abstract}

\section{Introduction}

It has been confirmed that inhibition efficiency of polar organic compounds for corrosion of various metals in acid solutions was closely related to the hard and soft acids and bases principle (HSAB principle) $)^{1), 2)}$. This relation has been valid for the inhibition efficiency of the compounds RX: chemically adsorbed on the bulk metal $\mathrm{M}$, corresponding to a soft acid, as

$$
\mathrm{RX}:+\mathrm{M} \longrightarrow \mathrm{RX}: \mathrm{M}
$$

The softness of the metal as the acid has also been estimated by using the relationship between the efficiency and the softness of compound as the base ${ }^{1) \sim 3}$.

Effects of the compounds on the passivity of $\mathrm{Ni}$ in an $\mathrm{HClO}_{4}$ solution has been discussed on the basis of the principle ${ }^{4}$. The compounds in which elements of polar atoms belong to the $6 \mathrm{~B}$ and 7B group of the periodic table stimulated the passive current density and the compounds of

\footnotetext{
* 3-14-1 Hiyoshi, Kohoku-ku, Yokohama, 223 Japan
}

which the polar atoms are of the 5B group inhibited the current density. These stimulation and inhibition has also been confirmed to be related with the HSAB principle.

Since such ions in high oxidation state as $\mathrm{Ni}^{3+}$ and $\mathrm{Fe}^{3+}$ are classified to the hard acid, the compound RX: acting as the hard base can readily be chemisorbed on an oxidized metal surface, for example on oxidized $\mathrm{Fe}$,

$$
\mathrm{RX}:+\mathrm{Fe}^{3+} \longrightarrow \mathrm{RX}: \mathrm{Fe}^{3+}
$$

In the present paper, it is discussed that the HSAB principle is related to the effect of the compounds with the polar atoms of the 5B group elements on the passive current density of $\mathrm{Fe}$ electrode in a borate buffer solution ( $\mathrm{pH}$ 8.45) and to the amounts of the compounds adsorbed on $\gamma-\mathrm{Fe}_{2} \mathrm{O}_{3}$ powder in methanol.

\section{Experimental}

\subsection{Polar organic compounds}

The compounds used as the corrosion inhibitors were listed in Table 1. The alkyl groups in them 
Table 1 Cross-sectional area $\sigma_{\text {ads }}$ and surface coverage $\theta$ of the 5B group inhibitors.

\begin{tabular}{ccc}
\hline \hline Inhibitor & $\sigma_{\text {ads }}\left(A^{-2}\right)$ & $\theta$ \\
\hline$R_{3} N$ & 88.4 & 0.0765 \\
$R_{3} P$ & 90.8 & 0.0365 \\
$R_{3}$ As & 91.9 & 0.0178 \\
$R_{3}$ Sb & 90.5 & 0.0145 \\
\hline
\end{tabular}

are all n-butyl. Amine $\mathrm{R}_{3} \mathrm{~N}$ and phosphine $\mathrm{R}_{3} \mathrm{P}$ were obtained as high-grade commercial reagents whereas arsine $R_{3} A s$ and stibine $R_{3} S b$ were synthesized by the reaction ${ }^{5)}$,

$$
\begin{aligned}
3 \mathrm{AlR}_{3}+\mathrm{X}_{2} \mathrm{O}_{3} \longrightarrow & 2 \mathrm{R}_{3} \mathrm{X}+3 \mathrm{RAlO} \\
& (\mathrm{X}=\text { As or } \mathrm{Sb})
\end{aligned}
$$

All of these compounds were carefully purified by distillation before use. Because the compounds of $\mathrm{P}, \mathrm{As}$, and $\mathrm{Sb}$ are susceptible to oxidation, they were kept in nitrogen atmosphere.

The inhibitor was dissolved in deaerated $3.0 \mathrm{M}$ $\mathrm{HClO}_{4}$ and $0.15 \mathrm{M} \mathrm{H}_{3} \mathrm{BO}_{3}-0.0357 \mathrm{M} \mathrm{Na}_{2} \mathrm{~B}_{4} \mathrm{O}_{7}$ buffer ( $\mathrm{pH} 8.45$ ) solutions which were prepared with reagent-grade chemicals and redistilled water.

2.2 Metal electrode and metal oxide powder

A rod of $99.99 \% \mathrm{Fe}^{*}$ (Johnson Matthey Chemicals, $5 \mathrm{~mm}$ diameter) was embedded in a Teflon holder and a circular cross section of the rod was polished with No. 2,000 emery paper and with $0.3 \mu \mathrm{m}$ alumina abrasive. The electrode was ultrasonically cleaned in acetone and etched in 3.0 $\mathrm{M} \mathrm{HClO}_{4}$.

Powder of $99.9 \% \gamma-\mathrm{Fe}_{2} \mathrm{O}_{3} * *$ (Kojundo Chem. Lab., $2 \mu \mathrm{m}$ diameter) was used in the adsorption experiment. A mean surface area of the powder was $4.06 \mathrm{~m}^{2} \mathrm{~g}^{-1}$ determined by electron microphotography.

\subsection{Polarization measurement}

Potential-current curve of the $\mathrm{Fe}$ electrode was measured in a glass cell equipped with an SCE reference and a Pt counter electrode. As a preliminary experiment, potentiostatic polarization in cathodic and anodic active region was carried out for the electrode in $3.0 \mathrm{M} \mathrm{HClO}_{4}$ with and without inhibitors at $30^{\circ} \mathrm{C}$.

The anodic polarization curve of the electrode in the borate buffer without and with the inhibitors was potentiodynamically measured at $20 \mathrm{mV} \mathrm{min}^{-1}$ of sweep rate from the open-circuit potential at $30^{\circ} \mathrm{C}$. Several runs were made, both

* Impurities: $\mathrm{Ca}, 0.0003 \% ; \mathrm{Mg}, 0.0002 \%$; $\mathrm{Cr}$, $\mathrm{Cu}$, and $\mathrm{Si},<0.0001 \%$.

** Impurities: $\mathrm{Mn}, 0.03 \%$; $\mathrm{Zn}, 0.003 \%$; Al, $0.006 \%$; Na, $0.005 \%$; Cr, $0.004 \%$; Co, $0.002 \%$. with and without the inhibitors at each concentration.

2.4 Determination of amount of the inhibitors adsorbed on $\boldsymbol{\gamma}-\mathrm{Fe}_{2} \mathrm{O}_{3}$ powder

In a three-necked flask was added the powder of $\gamma-\mathrm{Fe}_{2} \mathrm{O}_{3}$ into methanol solution of the inhibitor at $1 \times 10^{-4} \mathrm{M}$ of the concentration at $30^{\circ} \mathrm{C}$. The mixture was mechanically stirred under nitrogen atmosphere for $3 \mathrm{~h}$ and left without the stirring overnight for sedimentation of the powder in the solution. A change in the inhibitor concentration of the solution was then detremined by HPLC. The concentration of amine and of water desorbed from the $\gamma-\mathrm{Fe}_{2} \mathrm{O}_{3}$ surface was measured at different times by HPLC after the centrifugal separation of the powder.

\section{Results and Discussion}

A cross-sectional area $\sigma_{\text {ads }}$ of an inhibitor molecule adsorbed on a surface was calculated from the liquid density $\rho$ by the equation,

$$
\sigma_{\text {ads }}=1.833(M / N \rho)^{2 / 3}-10.33
$$

where $M$ and $N$ are molecular weight and the Avogadro number, respectively ${ }^{6}$. In Table 1 are listed $\sigma_{\text {ads }}$ of the 5B group inhibitors. Because the values of $\sigma_{\text {ads }}$ were nearly constant, effect of the area on the inhibition efficiency was taken to be equal for the inhibitors used in this study. Adsorption ability of the inhibitors on the metal or oxide surface should be reflected in the efficiency.

3.1 On the inhibition effect of the inhibitors on the active current density of $\mathbf{F e}$ in $\mathbf{H C l O}_{4}$

Fig. 1 shows typical polarization curves of the $\mathrm{Fe}$ electrode uninhibited and inhibited with the $5 \mathrm{~B}$ group inhibitors in $3.0 \mathrm{M} \mathrm{HClO}_{4}$. Arsine and stibine were effective inhibitors in the acid solution, forming black precipitates on the iron surface at the open-circuit potential. Good reproducibility was not obtained for the polarization curves, especially the cathodic ones, of the electrode inhibited with these inhibitors, probably because of the formation of precipitate film on the surface.

The black precipitate film of $\mathrm{R}_{3} \mathrm{Sb}$ on $\mathrm{Fe}$ was analyzed by p-polarized reflection infrared spectrometry. The spectrum of the surface film was similar to that of neat $\mathrm{R}_{3} \mathrm{Sb}$, as shown in Fig. 2, indicating that structure of $\mathrm{R}_{3} \mathrm{Sb}$ is of a major importance to that of the precipitate. Since no precipitation was observed in aqueous $\mathrm{HClO}_{4}$ solution of $\mathrm{R}_{3} \mathrm{Sb}$ by the addition of both $\mathrm{Fe}^{2+}$ and $\mathrm{Fe}^{3+}$, the black precipitate seems no simple complex of $\mathrm{Fe}$ ion with $\mathrm{R}_{3} \mathrm{Sb}$, however. 


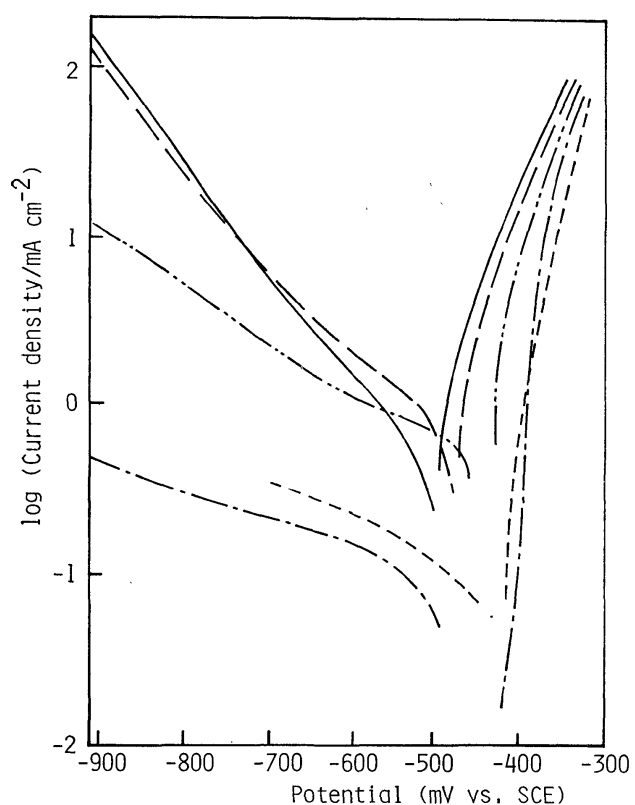

Fig. 1 Typical polarization curves of $\mathrm{Fe}$ electrode uninhibited (-) and inhibited with $\mathbf{R}_{3} \mathbf{N}$ (- -), $\mathrm{R}_{3} \mathrm{P}$ (---), $R_{3} \mathrm{As}(--)$, and $\mathrm{R}_{3} \mathrm{Sb}(----)$ at $0.01 \mathrm{M}$ in $3 \mathrm{M} \mathrm{HClO}_{4}$.

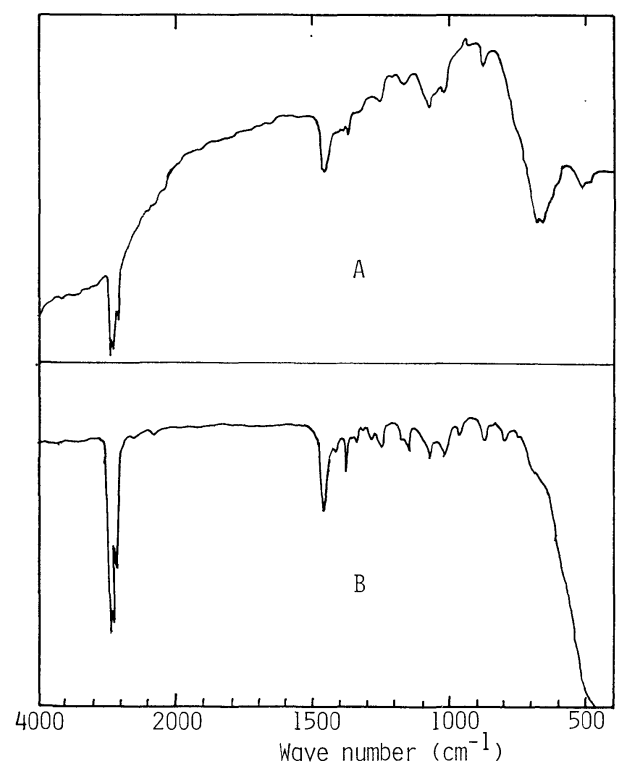

Fig. 2 Polarized reflection infrared spectrum of surface precipitate on $\mathrm{Fe}$ inhibited with $\mathrm{R}_{3} \mathrm{Sb}$ in $3 \mathrm{M} \mathrm{HClO}_{4}$ (A) and infrared spectrum of $\mathrm{R}_{3} \mathrm{Sb}$ (B).

Because the cathodic curve was not reproducible, the current density at $-380 \mathrm{mV}$ vs. SCE in the anodic branch of polarization curve was adopted to the discussion. The anodic inhibition efficiency, $I_{\mathrm{a}}$ was obtained by

$$
I_{\mathrm{a}}=1-i_{\mathrm{a}} / i_{\mathrm{a}}{ }^{0}
$$

where $i_{\mathrm{a}}{ }^{0}$ and $i_{\mathrm{a}}$ are current densities of the uninhibited and inhibited electrode at $-380 \mathrm{mV}$, respectively. According to the linear free energy relationship, $I_{\mathrm{a}}$ is expressed by an equation,

$$
\log \left[I_{\mathrm{a}} /\left(1-I_{\mathrm{a}}\right)\right]=\rho^{\prime} \chi+\alpha^{\prime}
$$

where $\chi$ refers to an electronegativity of the polar atom in the inhibitor molecule, and $\rho^{\prime}$ and $\alpha^{\prime}$ are constants, respectively. The electronegativity is a measure of the softness and hardness of the inhibitor as the base. Correlation in Eq. (3) was confirmed to be valid for the inhibition efficiency of various inhibitors for the active dissolution of $\mathrm{Ni}$ in $\mathrm{HClO}_{4}{ }^{4)}$. The value of $\log \left[I_{\mathrm{a}} /\left(1-I_{\mathrm{a}}\right)\right]$ was plotted against $\chi$ in Fig. 3, indicating straight lines and deviation of the plots for $R_{3} A s$ and $\mathrm{R}_{3} \mathrm{Sb}$. Since the deviation may be caused by the formation of the precipitate on the surface, it was concluded that the relationship in Eq. (3) was established with a minus value of $\rho^{\prime}$, which agreed with the results in the previous works ${ }^{1) \sim 4}$.

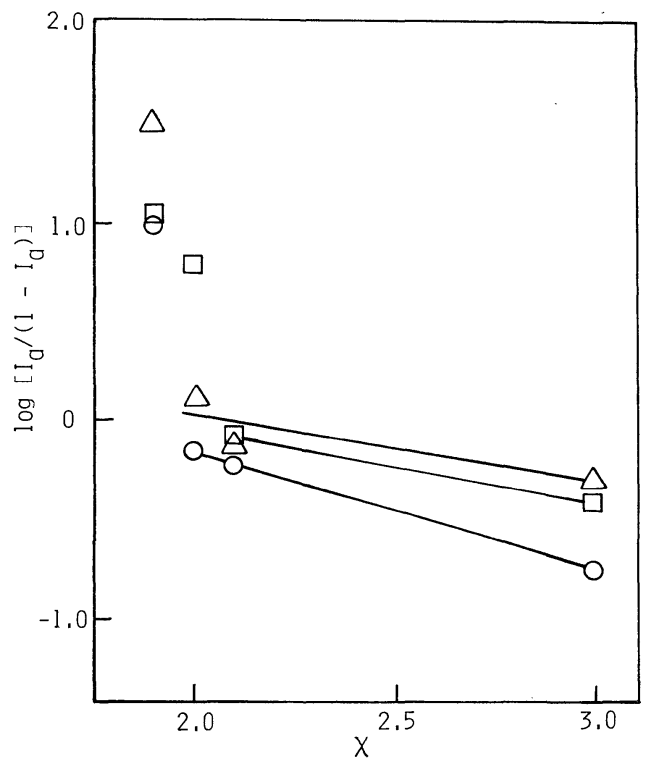

Fig. 3 Relationship between $\log \left[I_{\mathrm{a}} /\left(1-I_{\mathrm{s}}\right)\right]$ and electronegativity $\chi$ of the $5 \mathrm{~B}$ group inhibitors for Fe corrosion at $-380 \mathrm{mV}$ vs. SCE at $0.001 \mathrm{M}$ $(\bigcirc), 0.005 \mathrm{M}(\square)$, and $0.01 \mathrm{M}(\triangle)$.

3.2 On the effect of the inhibitors on the passive current density of $\mathrm{Fe}$ in the borate buffer (pH 8.45)

No peak was observed in the active and passive range of the anodic polarization curves for the uninhibited $\mathrm{Fe}$ electrode in the deaerated borate buffer solution at $\mathrm{pH} 8.45$, as shown in curves 


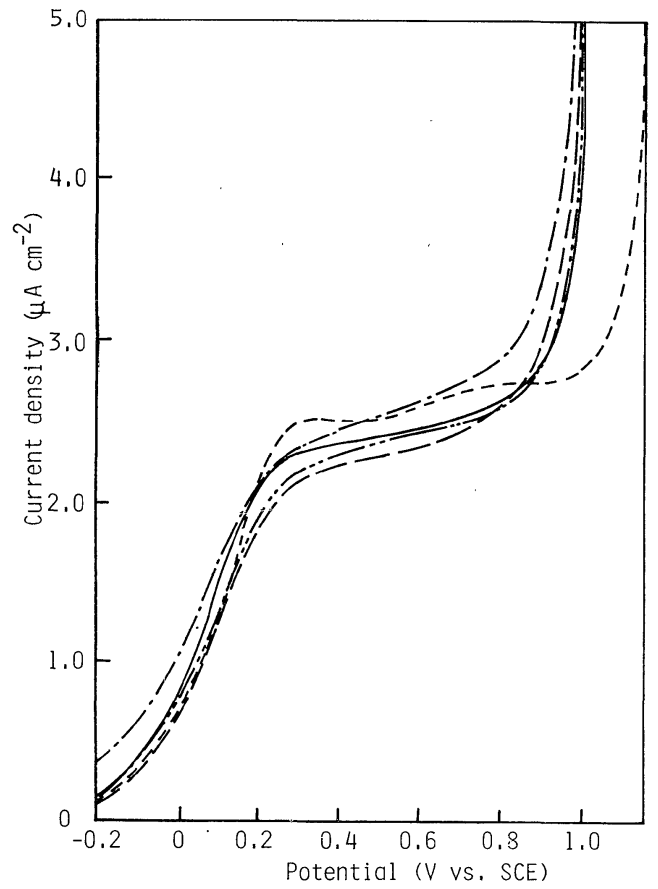

Fig. 4 Anodic polarization curves of $\mathrm{Fe}$ electrode uninhibited (-) and inhibited with $\mathrm{R}_{3} \mathrm{~N}$ (- -), $\mathrm{R}_{3} \mathrm{P}$ (---), $\mathrm{R}_{3} \mathrm{As}(---)$, and $\mathrm{R}_{3} \mathrm{Sb}$ (---) at $0.005 \mathrm{M}$ in borate buffer soultion (pH 8.45).

of Fig. 4. It has been reported that the passive film formed on the $\mathrm{Fe}$ electrode in the borate buffer consisted of two layers, an inner layer of $\gamma-\mathrm{Fe}_{2} \mathrm{O}_{3}$ and an outer one of $\mathrm{FeOOH}$ or $\mathrm{Fe}(\mathrm{OH})_{3}{ }^{7) \sim 9)}$. The most of cation in the passive film formed on the Fe surface in the neutral buffer is taken to be $\mathrm{Fe}^{3+}$ which is classified to the hard acid $^{10)}$. The interaction between the hard acid and the hard base is expected to favor the adsorption of inhibitor on the passive film of Fe.

Fig. 4 shows typical anodic polarization curves of the $\mathrm{Fe}$ electrode in the borate buffer solution with and without the inhibitors at $0.005 \mathrm{M}$. The curves in the figure were drawn by using the average current densities obtained in several runs of the each experiment. Fairly good reproducibility of the density was observed in the passive region of the curve between 0.3 and $0.8 \mathrm{~V}$ vs. SCE. Amine and phosphine inhibited the passive current density in this region while arsine and stibine stimulated. The inhibition of the current density may be caused by the retardation of passive film growth on the Fe surface by adsorption of the inhibitor. It has been reported that some nitrogen-containing inhibitors retarded the oxide growth rate and film thickness on Armco iron in a borate buffer ${ }^{11)}$. The increase of passive current density has been observed for the $\mathrm{Ni}$ electrode inhibited with the $6 \mathrm{~B}$ and $7 \mathrm{~B}$ group inhibitors acting as the soft bases in an $\mathrm{HClO}_{4}$ solution ${ }^{4)}$. This increase has been interpreted by hindrances of the inhibitor molecules adsorbed on bulk metal to the formation of passive film on the surface. The stimulation of the passive current density for the Fe electrode in the borate buffer with $R_{3}$ As and $\mathrm{R}_{3} \mathrm{Sb}$ can also be explained by the hindrances of the passive film formation, because these compounds also act as the soft bases.

A similar equation to Eq. (3) can be derived as

$$
\log \left[I_{\mathrm{p}} /\left(1-I_{\mathrm{p}}\right)\right]=\rho^{\prime} \chi+\alpha^{\prime}
$$

with respect to the inhibition efficiency for the passive current density $I_{\mathrm{p}}$, given by

$$
I_{\mathrm{p}}=1-i_{\mathrm{p}} / i_{\mathrm{p}}{ }^{0}
$$

where $i_{\mathrm{p}}{ }^{0}$ and $i_{\mathrm{p}}$ denote the passive current densities of the electrode uninhibited and inhibited with the inhibitors, respectively.

Since negative value of $I_{p}$, i.e. the stimulation of $i_{p}$, cannot be adopted to the relation of Eq. (4), $I_{\mathrm{p}} /\left(1-I_{\mathrm{p}}\right)$ was plotted against $\chi$ in Fig. 5 . The curves show a tendency of the increase in $I_{\mathrm{p}} /\left(1-I_{\mathrm{p}}\right)$ with $\chi$, suggesting that the inhibitor classified to the hard base is adsorbed on the oxidized $\mathrm{Fe}$ surface and decreases the passive current density

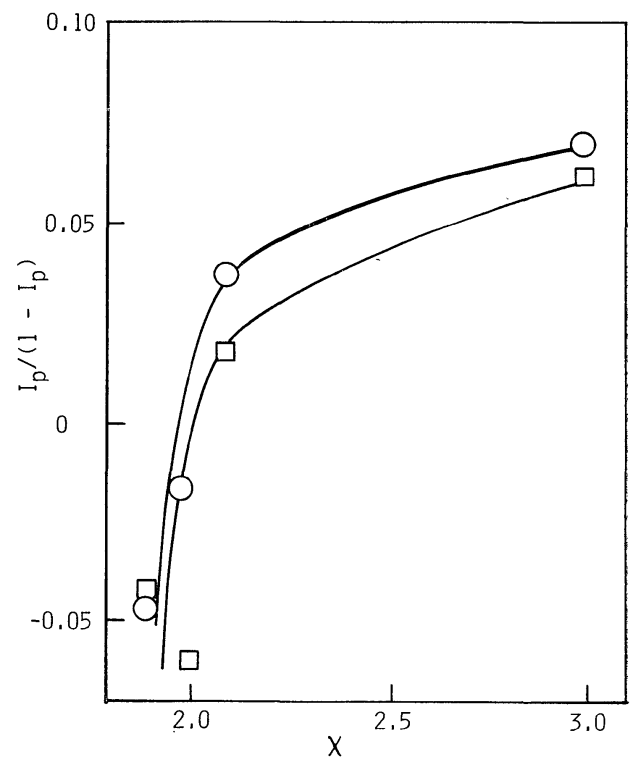

Fig. 5 Correlation of $I_{\mathrm{p}} /\left(1-I_{\mathrm{p}}\right)$ to $\chi$ for $\mathrm{Fe}$ electrode inhibited with the $5 \mathrm{~B}$ group inhibitors at 0.005 $\mathrm{M}$ in borate buffer $(\mathrm{pH} \mathrm{8.45)}$ at $0.4 \mathrm{~V}(\mathrm{O})$ and $0.6 \mathrm{~V}$ vs. SCE ( $\square)$. 
to more extent than the soft base. The compounds acting as the hard base may be concluded to adsorb readily on the surface acting as the hard acid.

The low inhibition effectiveness of amine on the passive current density can be explained by the competitive adsorption of the inhibitor with large amount of the other bases like $\mathrm{H}_{2} \mathrm{O}, \mathrm{OH}^{-}$, and $\mathrm{BO}_{3}{ }^{3-}$ existing in the solution. This result implies a difficulty in the corrosion inhibition of oxidized metal by the action of inhibitor chemisorbed on the surface. Passivators or precipitation-type inhibitors are expected to be effective for inhibition of oxidized metal rather than the adsorption inhibitors. The hard base inhibitor can form a protective film of dense precipitate on the surface with the multivalent ion like $\mathrm{Fe}^{3+}$ classified to the hard acid and suppress the corrosion of oxidized surface.

\subsection{Adsorption of the inhibitors on the powder} of $\boldsymbol{\gamma}-\mathrm{Fe}_{2} \mathrm{O}_{3}$

Surface excess of the inhibitors, $\Gamma$ was obtained from change of the concentration by the adsorption on the powder of $\gamma-\mathrm{Fe}_{2} \mathrm{O}_{3}$ in deaerated methanol. The change in the concentration of amine with time is shown in Fig. 6. The inhibitor was rapidly adsorbed on the oxide surface and the adsorption reached an equilibrium within $1 \mathrm{~h}$ after immersion of the powder.

The maximum surface excess, $\Gamma_{\max }$ was calculated from $\sigma_{\text {ads }}$ by

$$
\Gamma_{\max }=1 / \sigma_{\mathrm{ads}} N
$$

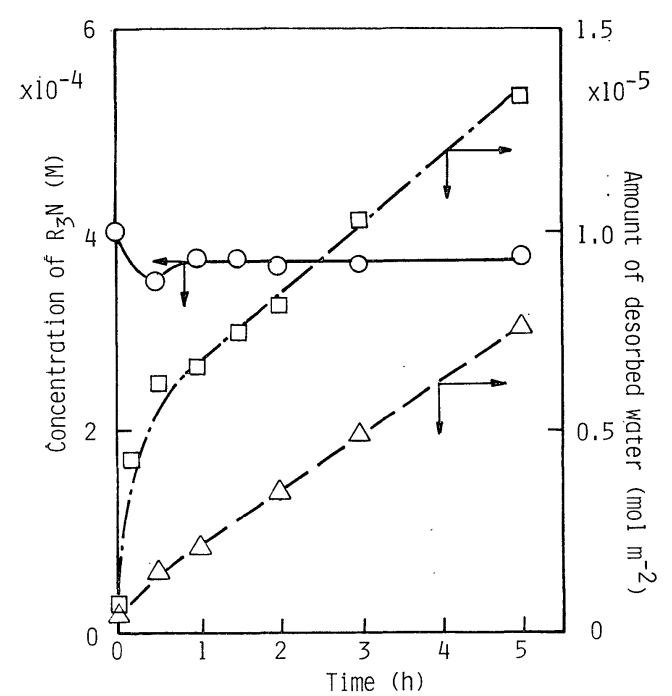

Fig. 6 Change in $\mathrm{R}_{3} \mathrm{~N}$ concentration $(O)$ and amount of water desorbed from $\gamma-\mathrm{Fe}_{2} \mathrm{O}_{3}$ powder in methanol without $(\triangle)$ and with $R_{3} N(\square)$.
In table 1 is also tabulated the surface coverage $\theta$, obtained by

$$
\theta=\Gamma / \Gamma_{\max }
$$

Since $I_{\mathrm{a}} /\left(1-I_{\mathrm{a}}\right)$ corresponds to an equilibrium constant, Eq. (3) can be rewritten by using $\theta$ as $\log [\theta /(1-\theta)]=\rho^{\prime} \chi+\alpha^{\prime}$

The values of $\log [\theta /(1-\theta)]$ were plotted against $\chi$ in Fig. 7. Because of a linear relationship between them with a positive slope, $\rho^{\prime}=0.67$, it was concluded that the hard base was more readily adsorbed on the surface of $\gamma-\mathrm{Fe}_{2} \mathrm{O}_{3}$ classified to the hard acid than the soft base. The relationship between the adsorption of polar organic compounds on the oxidized metal and the HSAB principle was confirmed in conclusion.

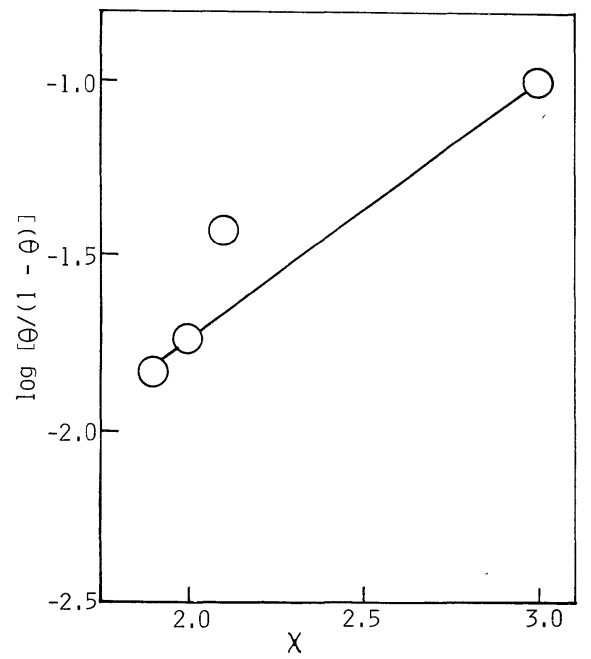

Fig. 7 Relationship between $\log [\theta /(1-\theta)]$ and $\chi$ for the $5 \mathrm{~B}$ group inhibitors adsorbed on $\gamma-\mathrm{Fe}_{2} \mathrm{O}_{3}$ powder in methanol.

The low values of $\theta$ can be explained by the competitive adsorption of the inhibitor on the oxidized surface with methanol acting as the hard base. Therefore, high inhibition efficiency of the inhibitors is not expected by their simple chemisorption on the oxidized metal as compared with the efficiency for the metal corrosion in an acid solution.

There are, in general, $\mathrm{OH}^{-}$or $\mathrm{H}_{2} \mathrm{O}$ combined with metal ion on oxidized surfaces. Three types of adsorption can be considered for the polar organic compound $\mathrm{R}_{n} \mathrm{X}$ : on the oxide surface; they are adsorptions (1) by the formation of a hydrogen bond between the polar atom and $\mathrm{OH}$ group of the oxide surface, (2) by electrostatic interaction of a protonated polar atom with Lewis base of the oxide surface, and (3) by form- 
ing a coordinate bond between the polar atom and Lewis acid of the surface as shown in Fig. 8. A linkage between metal ion and the polar atom of the inhibitor can form only in the adsorption of type (3). These types have been confirmed for the adsorption of pyridine on oxides like Vycor glass and $\gamma$-alumina by Raman spectrometry ${ }^{12}$. Since all the three types of adsorption arise from the hard acid-hard base interaction, the adsorption behavior of the hard base inhibitor on the oxidized metal is possible to give rise to these adsorption mechanisms.
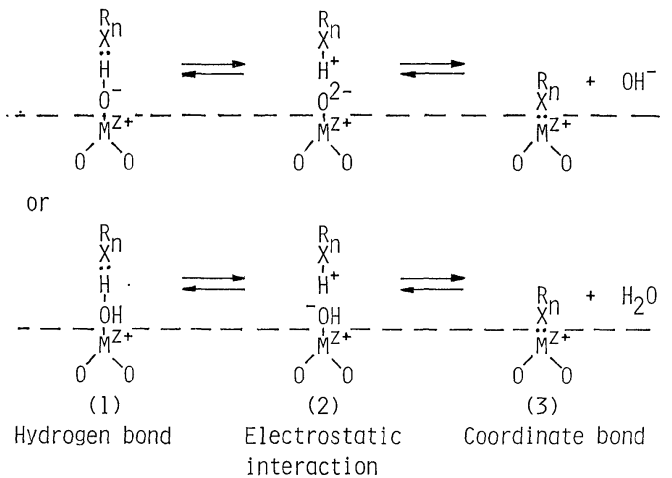

Fig. 8 Adsorption of $\mathrm{R}_{n} \mathrm{X}$ : on the oxidized metal surface.

There exist equilibrium states between these types of adsorption. It is considered that the equilibriums tend to shift towards the type (3) because the coordinate bond seems a more stable linkage between $\mathrm{X}$ and the oxidized metal in the neutral aqueous or methanol solution than the ionic interaction and the hydrogen bonding. Surface enhanced Raman scattering spectra of pyridine adsorbed on surfaces of $\mathrm{NiO}(100)$ and $\mathrm{TiO}_{2}(001)$ have shown that a majority of the adsorption bonds was the coordinate bond between the nitrogen atom and the metallic site ${ }^{13)}$. Water molecule must be desorbed from the oxide surface, provided that the type (3) of adsorption occurs on the surface. The desorption of hydroxide ion may result in the formation of $\mathrm{M}^{\mathrm{z}+}$ $\mathrm{O}^{2-}$ bond and desorbed water molecule.

Fig. 6 also shows amounts of water desorbed from the $\gamma-\mathrm{Fe}_{2} \mathrm{O}_{3}$ powder in methanol and in methanol solution of amine at $4 \times 10^{-4} \mathrm{M}$ of the concentration. The curves obviously indicate the desorption of water from the surface by the action of amine. Similar behavior of the water desorption from surface of iron powder has been reported $\left.^{14)}, 15\right)$. As can be seen in Fig. 6, the amount of desorbed water increases as the adsorption of amine on the oxide surface proceeds. It is thus supposed that the type (3) is of major importance to the adsorption of the inhibitor on the oxidized surface.

\section{Conclusion}

Effect of the 5B group inhibitors was measured on the anodic polarization curves of $\mathrm{Fe}$ electrode in deareated $\mathrm{HClO}_{4}$ and neutral borate buffer solutions. The inhibition efficiency of the inhibitors in the active and passive region of the curves was closely related to the HSAB principle. The compounds classified to the hard base was readily adsorbed on the oxidized iron surface acting as the hard acid, whereas the inhibitor of the soft base was easily adsorbed on the iron surface, the soft acid.

The amount of the polar compounds adsorbed on the powder of $\gamma-\mathrm{Fe}_{2} \mathrm{O}_{3}$ was also determined in methanol by HPLC analysis. The result showed that the hard base was adsorbable to more extent on the powder than the soft base, supporting the relationship between the adsorption behavior and the HSAB principle. The low amount of the hard base adsorbed on the oxide powder and the low inhibition efficiency of the hard base inhibitor for the passive current density of $\mathrm{Fe}$ may be attributed to the competitive adsorption of the inhibitor with the other hard bases existing in the solutions. The relationship between the adsorption behavior and the HSAB principle was thus confirmed on the oxidized iron as well as the iron surface.

(Received May 31, 1985)

\section{References}

1) K. Aramaki: "Proceedings 5th European Symposium on Corrosion Inhibitors," vol. 1, p. 267, Università Degli Studi di Ferrara, Ferrara (1980).

2) K. Aramaki, S. Iizumi \& F. Nakagawa: Boshoku Gijutsu, 29, 566 (1980).

3) K. Aramaki: Boshoku Gijustsu, 32, 144 (1983).

4) K. Aramaki: Boshoku Gijutsu, 33, 431 (1984).

5) Von Dr. W. Stamm \& A. Breindel: Angew. Chem., 76, 99 (1964).

6) A. L. McClellan \& H. F. Harnsberger: J. Colloid Interface Sci., 23, 577 (1967).

7) N. Sato: Denki Kagaku, 46, 584 (1978).

8) N. Sato \& G. Okamoto: "Comprehensive Treatise of Electrochemistry"; J. O’M. Bockris et al. ed., vol. 4, p. 217, Plenum, New York (1981).

9) N. Sato, K. Kudo \& R. Nishimura: J. Electrochem. Soc., 123, 1419 (1976). 
10) Z. Szklarska-Smialowska \& W. Kozlowski: $J$. Electrochem. Soc., 131, 234 (1984).

11) P. Spinelli, R. Fratesi \& G. Roventi: Werks. Korr., 34, 161 (1983).

12) H. Yamada \& Y. Yamamoto: J. Chem. Soc., Faraday I, 75, 1215 (1979).

13) H. Yamada \& Y. Yamamoto: Surface Science, 134, 71 (1983).
14) S. Fujii \& K. Aramaki: "Proceedings 3rd International Congress on Metallic Corrosion", vol. 2, p. 70, Swets-Zeitlinger, Amsterdam (1969).

15) S, Fujii \& K. Kobayashi: “Comptes Rendus du 2 ème Symposium Européen sur les Inhibiteurs de Corrosion", vol. 2, p. 829, Università Degli Studi di Ferrara, Ferrara (1966). 